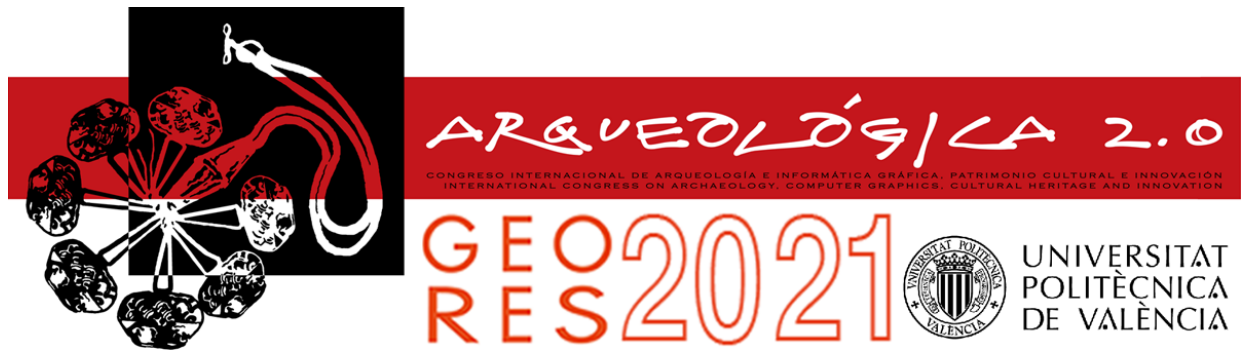

Proceedings of the joint international event $9^{\text {th }}$ ARQUEOLÓGICA

$2.0 \& 3^{\text {rd }}$ GEORES

Valencia (Spain).

26-28 April 2021

\title{
HBIM FOR RESTORATION WORK AND MONITORING OF COMPLEX ARCHITECTURES: THE FAMILY CHAPEL OF RAMÓN PERES Y ROVIRA IN CASTELLÓN DE LA PLANA (SPAIN)
}

\author{
Gianna Bertacchia, ${ }^{*}$, Francisco Juan-Vidal $^{\mathrm{b}}$, Luca Cipriania \\ a Department of Architecture, University of Bologna, Viale del Risorgimento 2, 40136 Bologna, Italy. gianna.bertacchi2@unibo.it; \\ luca.cipriani@unibo.it \\ ${ }^{\mathrm{b}}$ Department of Graphic Expression in Architecture, Instituto de Restauración del Patrimonio, Universitat Politècnica de València, \\ Camino de Vera, s/n, 46022 Valencia, Spain. fjuan@ega.upv.es
}

\begin{abstract}
:
The paper analyses the procedure to create a 3D model of a neogothic family chapel situated in Castellón de la Plana (Spain). The characteristics of the case study make it an emblematic case of Building Information Modeling (BIM) applied to Cultural Heritage (Historic BIM). The paper explores the workflow used to create the model and how the difficulties encountered have been addressed. The key motivations for this research project are: (i) local authority needs and objectives (restoration works for the conservation of architecture; necessity to monitor the asset after restoration); (ii) the intrinsic peculiarities of the small building (vast diversity of materials, richness and diversity of decorative elements); (iii) the creation of a pilot project for future applications in similar architectures. The chosen workflow tries to tackle the principal issues shared by the academic world with respect to 3D and HBIM models, e.g. the difficulty in reconstructing complex architectures without time-consuming processes, the reliability and high detail in the rendering of colours and textures, the insertion of detailed information for each element. The experiments carried out have made this case study interesting because of its complexity despite its reduced dimensions.
\end{abstract}

Keywords: HBIM, restoration works, neogothic architecture, family chapel, 3D reconstruction, Cultural Heritage

\section{Introduction}

In the field of Cultural Heritage $(\mathrm{CH})$ documentation, the last decades have been characterised by a huge increase in digital documentation with the use of active and passive sensors, in particular Terrestrial Laser Scanners (TLS) and digital photogrammetry. The latest research in the field of digital heritage documentation now focuses on the application of the Building Information Modeling (BIM) process to cultural assets (some recent experiments are cited in the reviews by Dore \& Murphy, 2017; López, Lerones, Llamas, Gómez-García-Bermejo, \& Zalama, 2018; Pocobelli, Boehm, Bryan, Still, \& Grau-Bové, 2018; Salvador-García, García-Valldecabres, \& Viñals-Blasco, 2018). This field of research is known today as Historic BIM (HBIM), as defined by Dore \& Murphy (2012). Since BIM is a modelling method created for the modelling and management of new buildings, its application to historical buildings generates evident critical issues that we can divide into three areas: (i) modelling criticalities; (ii) standardisation criticalities; (iii) criticalities related to the texture and final appearance of the model. The paper tries to address mainly points (i) and (ii) in a BIM environment, while point (iii) is addressed using digital photogrammetry and different 3D modelling software.

The modelling criticalities (i) derive mainly from the very characteristics of BIM software, created to be used with newly designed and constructed buildings, generally characterised by simple and rectified shapes and standardised elements. BIM software houses have therefore focused on providing basic modelling tools, that can be easily applied for the creation of simple models. These tools, limited and rigid, are poorly adaptable to replicate the geometric characteristics of the heterogeneous elements that constitute $\mathrm{CH}$. Moreover, the management of raw survey data (e.g. TLS point clouds or digital photogrammetry) in BIM environment is still limited and not very fluid. Since point clouds are generally the base for a $3 \mathrm{D}$ reconstruction of the cultural asset, their fluid use in BIM would provide a reliable tool for the scan-to-BIM methodology. For example, the inability to easily relate the outer and inner part of the same element, such as a wall, from a point cloud to a BIM component, causes difficulties in this time-consuming modelling phase. This problem could be implemented by software houses by improving mesh import and 
decimation, either directly from the point cloud or from mesh models already made.

Modelling problems are generally solved with the following approaches: (a) modelling in software external to BIM model management software (Massafra, Prati, Predari, \& Gulli, 2020); (b) development of ad hoc plugins and workflows for the management, modelling or import of mesh models in BIM environment (Bolognesi \& Caffi, 2019); (c) development of algorithms for automatic segmentation and classification of point clouds (Grilli \& Remondino, 2019; Pierdicca et al., 2020); (d) parametric modelling of complex components using Dynamo in Autodesk Revit (Massafra, Prati, Predari, \& Gulli, 2020; Jiang et al., 2020). Sometimes, these techniques are not completely conclusive and lead to partial results or where the loss of detail makes the model unusable for certain types of analysis. In addition, the developed workflows have considerable criticality in terms of time consumption and data loss when switching from one software to another; moreover, they generally require user-specific skills in the use of multiple modelling software and data interchange.

The most recent experiments try to solve the critical issues highlighted, for example by developing a workflow with software from the same software house, so as to avoid problems generated in the transition from one to the other, or with open source software and interchange formats (Diara \& Rinaudo, 2018). The same software houses are moving in the direction of developing new tools for mesh creation within the same program, trying to facilitate the onerous process of model generation. Our contribution tries to follow the latter workflow for the creation of the BIM model: external 3D modelling software are not used for the creation and import of elements into the BIM environment, but are only used to produce realitybased 3D models with a focus on texture appearance and model optimisation (as shown in previous works and experiments, such as in Cipriani \& Fantini, 2018; Bertacchi, Bertacchi \& Cipriani, 2021).

The modelling issue is related to the second one, i.e. the standardization (ii). As is well known, $\mathrm{CH}$ is characterised by elements with different geometric and conservative characteristics, even if they belong to the same category (e.g. the wooden beams of a ceiling or the columns of a portico). It is clear that each project must be preceded by the definition of the level of detail required for the work to be carried out, avoiding long-lasting modelling procedures. In this sense, since there is no specific international regulation, some scholars are trying to formalize the representation scales applicable to HBIM, deriving from the levels used to define BIM models (Biagini \& Donato, 2016; Castellano-Román \& PintoPuerto, 2019; Banfi, 2017; Banfi, 2020). As a basic concept, the necessary level of detail will be derived from the use of the information and the model in the restoration project, as it is for the representation scales of the traditional 2D drawings (Brumana, Banfi, Cantini, Previtali, \& Della Torre, 2019).

The complexity of finding universal standards for the creation of HBIM models leads to an inevitable simplification and the impossibility of creating libraries of elements with the same characteristics for subsequent reuse. This mainly leads to a lengthening of modelling times and the consequent impossibility of using families of elements already modelled, one of the most advantageous aspects of BIM software. Despite these current problems, HBIM remains one of the most expanding fields, precisely because of the advantages that a BIM model, once completed, offers in terms of managing not only a single restoration, but also the entire life cycle of the building (Mol, Cabaleiro, Sousa, \& Branco, 2020) and the information that can be included in it for a collaborative approach to the project (Heesom et al., 2020). However, it is necessary to assess on a case-bycase basis whether the expenditure of energy and economic resources involved in implementing an HBIM model is really justified by the needs in terms of restoration, monitoring and management of the asset, or whether it would be more convenient to choose another type of method that is more congenial and effective for the type of object being worked on.

Since the projects and technical drawings of the restoration work are based precisely on the possibility of interacting with the complexity and variability that characterises historic buildings, excessive standardisation can lead to an unusable result for restoration users, who therefore resort to classic 2D drawings, nullifying the potential of the BIM model.

Finally, the critical issues related to the texture of elements with complex geometry (iii) determine a final visualization of the model that often does not meet the needs of a restorer (e.g. for mapping pathologies directly on the 3D model). This problem is generally solved with the introduction of high quality orthoimages as an attachment to the specific element or part of the artifact, or with the support of other systems parallel to the model for texture visualization (Tsilimantou, Delegou, Nikitakos, Ioannidis, \& Moropoulou, 2020). Some experiments concern the use of adaptive components in Revit's BIM environment, that are used as elements to perform pathologies mapping (Chiabrando, Lo Turco, \& Rinaudo, 2017); in Sun, Xie, Zhang, \& Cao (2019) Revit's components are used for detail modelling ("brick-bybrick"), which provides the possibility to link attributes to the individual brick. For complex geometries, previous experiences have focused on other types of workflows (Adembri et al., 2016; Apollonio, Gaiani, \& Bertacchi, 2019; Cipriani, Bertacchi, \& Bertacchi, 2019; Cipriani \& Fantini, 2018). In these cases, information systems are developed centred on a reality-based 3D model with multi-scale and multi-user visualization. The strengths of this type of methodology are the high quality of the texture and the ease of use of the online platform even by nonexpert users, through an interface that allows direct mapping to the 3D model, also providing other useful data for restoration operations (such as the total surface affected by a given pathology, etc.). The critical points of this workflow, however, lie in the need for computer skills for the creation of the platform much more specific than those required for the use of BIM or other 3D modelling software.

Summing up, despite the multiplication in the last period of experiments in this field trying to solve the most emerging problems and the simultaneous development of dedicated software tools, these issues related to HBIM are still open.

This contribution is part of this framework as an experiment in the creation of an HBIM model of a complex architecture. The case study is a small oratory chapel for which restoration work will be undertaken (Fig. 1). The 
small building is characterised by the coexistence of many different materials and an important decorative apparatus in terracotta elements, which determines the complexity of the transposition into the BIM environment. As part of the restoration project, the research group decided to go beyond a "classic" digital documentation with TLS sensors and digital photogrammetry, proceeding with the creation of a BIM model with the following aims: (1) support to restoration work; (2) post-restoration monitoring; (3) pilot model for the restoration of stylistically and historically similar buildings; (4) creation of a library of standardized decorative elements present in similar buildings of the same period; (5) enhancement of $\mathrm{CH}$ with the use of the 3D model for educational purposes. However, beyond the BIM model, the research project maintains a parallel experimentation on high-detail models, especially of those decorative elements for which physical reproduction is necessary. This can be achieved with 3D printing operations, both positively and negatively for the prototyping of reusable formwork.

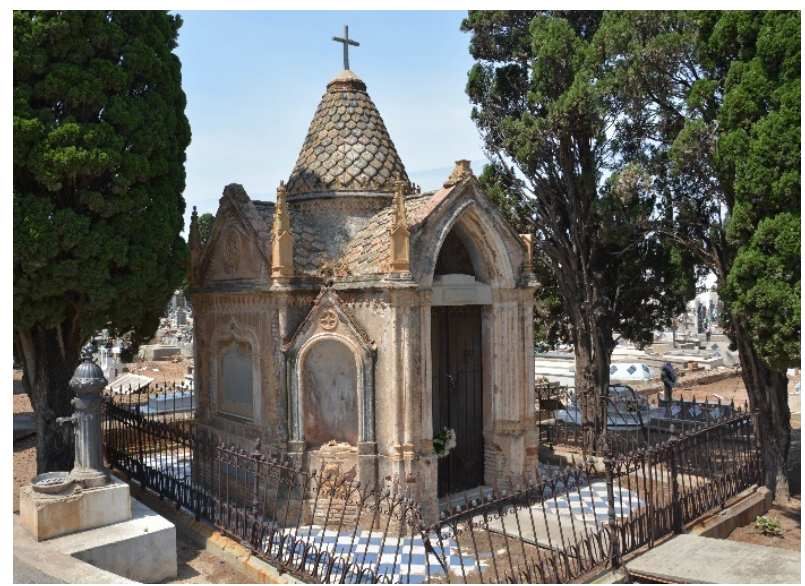

Figure 1: External view of the family chapel of Ramón Peres y Rovira.

The contribution makes an in-depth analysis of point (1), describing in detail the creation of the BIM model used support restoration work. The restoration work has not yet started, so the BIM model was used in the design phase of the restoration. Points (3), (4) and (5) are also explained but referring to the restoration project. Point (2) will be deepened after the restoration work, and it is analysed here in his design phase. In other words, we describe how the BIM model has been imagined to be used as a tool in every phase of the restoration work, present and future.

The article is divided as follows: in section 1 the project is inserted in the areas of research that make up the current HBIM panorama; in section 2 the case study and the surveying campaigns are described, highlighting the motivations that led to the development of the HBIM model; in section 3 the methodology followed for the implementation of the BIM model is defined, reporting some examples of the creation of families; in section 4 the possible future developments of the project and the conclusions deriving from the research are described.

\section{Case study}

This contribution reports an experimentation of the HBIM workflow applied to the family chapel (panteón) of Ramón Peres y Rovira, located in Sant Josep cemetery of
Castellón de la Plana (Comunitat Valenciana, Spain). The Municipality of Castellón decided to undertake restoration work on the chapel, which now suffers some serious pathologies, affecting both the decorative apparatus and the structure (Fig. 2).

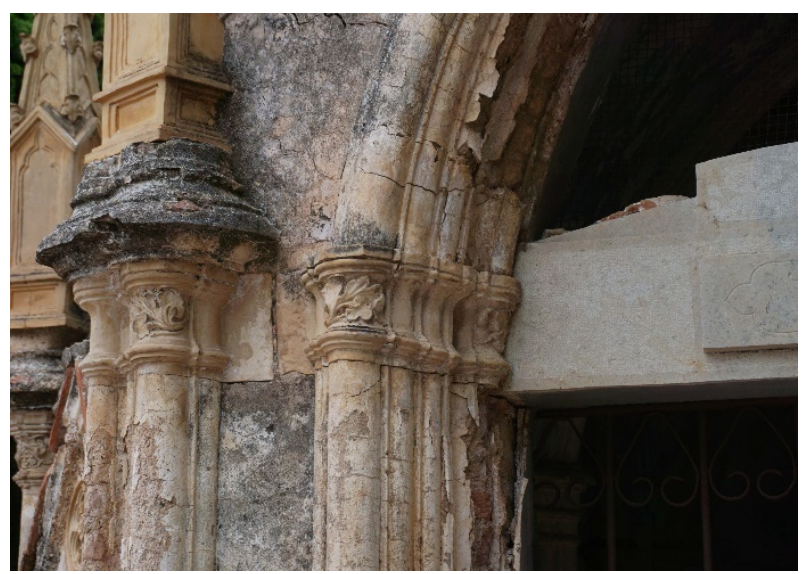

Figure 2: Some of the pathologies affecting the interior and exterior walls of the chapel.

The diversity of materials and pathologies found during the first inspections made it necessary to bring together a group of restorers specialised in different sectors of the Instituto de Restauración del Patrimonio (Institute for the Heritage Restoration) of the Universitat Politècnica de Valencia, responsible for the presentation of the preliminary project.

In order to provide the documentation underlying the preliminary restoration proposal, the documentation was created using TLS sensors and digital photogrammetry (see paragraph 2.2). This preliminary study served to identify the characteristics and problems of the small building.

In fact, as already mentioned in the introduction, the panteón has some characteristics that make its restoration and monitoring complex. First of all, (1) the presence of very different materials involves the interaction of professionals specialised in specific fields, such as the restoration of metals, glazed ceramics, terracotta, stone elements, plasters. Subsequently, (2) the presence of many decorative terracotta elements (Fig. 3 ) that can be found in similar buildings, led to think of standardized elements, probably made in series, following catalogues, by the factories in the area (famous for their ceramic production). In the chapel there are also some elements with a structural or complementary function that also have a decorative function (3) and therefore must be catalogued in the same way as decorative elements. This is the case of terracotta tiles, which have a particular petal shape, at least three different sizes and two different paste colours, arranged to form geometric patterns with alternating rhombuses (Fig. 4).

All these characteristics led to a cataloguing prior to the creation of the HBIM model, in order to establish the totality of the chapel components and decide for each component what information should be included in the BIM model. The cataloguing procedure is described in paragraph 3.1. 


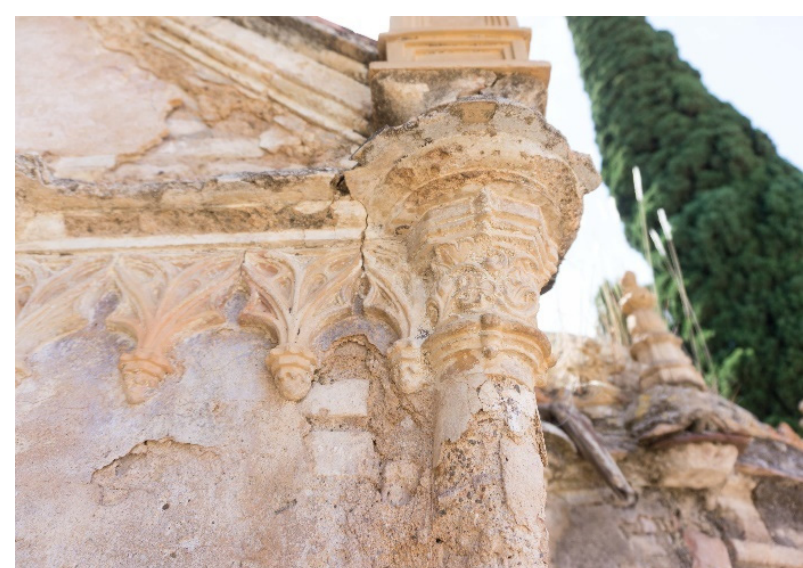

Figure 3: The decoration of the upper part of the outer wall.

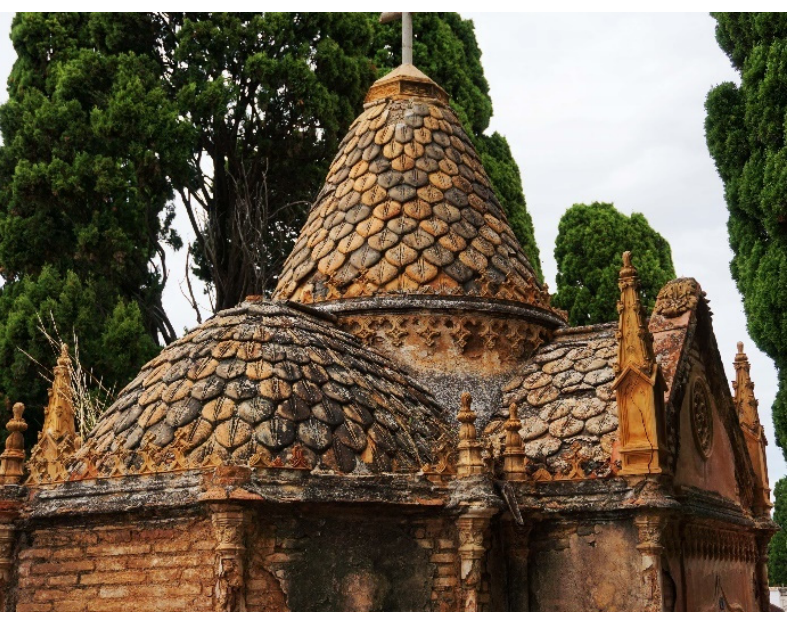

Figure 4: Terracotta roof tiles: the two different colours that form a geometric pattern are still visible despite the decay of the surface.

\subsection{Historical introduction}

The chapel of Ramón Peres y Rovira is a small building located in the centre of the old part of the cemetery of Sant Josep in Castellón de la Plana, in the province of València (Spain). The panteón is defined "oratory", since inside it has a small altar, two seats and a stoup, allowing to celebrate Mass in honour of the family members buried there. Little is known about its construction: we know that his wife was given the land for the construction of the chapel in 1866, a few years after the inauguration of the cemetery in 1861 (Molina Coronado, 2017). We can therefore deduce that the panteón was one of the first buildings in the cemetery. Unfortunately, at the time of writing this article we have no further information about the designer architect or construction companies; furthermore, the current period of restrictions for the COVID-19 pandemic makes it difficult to find further information in the local archives.

On the basis of a comparative stylistic analysis, we can say that the style of construction and decoration is neogothic and presents decorative elements common to chapels and buildings of the same period and in the same area. This detail is very useful to plan an in-depth analysis of the ceramic pieces. These in fact characterise the neogothic architecture of the provinces of Valencia and Barcelona and generally follow standardised profiles and shapes. Moreover, the Castellón area is both historically and currently an important centre of ceramic production (today it represents $90 \%$ of Spanish production). The first industrial production dates back to the $18^{\text {th }}$ century with the creation of the Real Fábrica de Loza y Porcelana de Alcora, and especially in the $19^{\text {th }}$ and $20^{\text {th }}$ centuries with the installation of many terracotta, ceramic and porcelain factories in Castellón and its surroundings (Ortells Chabrera, 2005). The analysis of ceramics can therefore be traced back to the production plant and its specific catalogues. This would allow, at best, to find in the catalogue of the time more information on the decorative pieces, especially those currently partial or missing (which can be glimpsed in the only historical photo in our possession). The search for similar elements and catalogues relating to the period of production of the decorations would also be a perfect basis for the creation of a library of three-dimensional models that could be adapted and reused in similar monuments in the same area.

Now the chapel is suffering from a deterioration that in recent years has been aggravated by a lack of maintenance. The close presence of three large cypress trees leads to the accumulation of organic material on the roof and in the enclosure, with consequent humidity present both outside and inside. The detachment of the plasters is widespread both internally and externally. In addition, some events that have occurred over the years have created serious damage to the metal fence (Fig. 5) and the south side of the building (the probable fall of the statue of the angel, that once crowned the central dome, caused the breakage of the decoration on the south side).

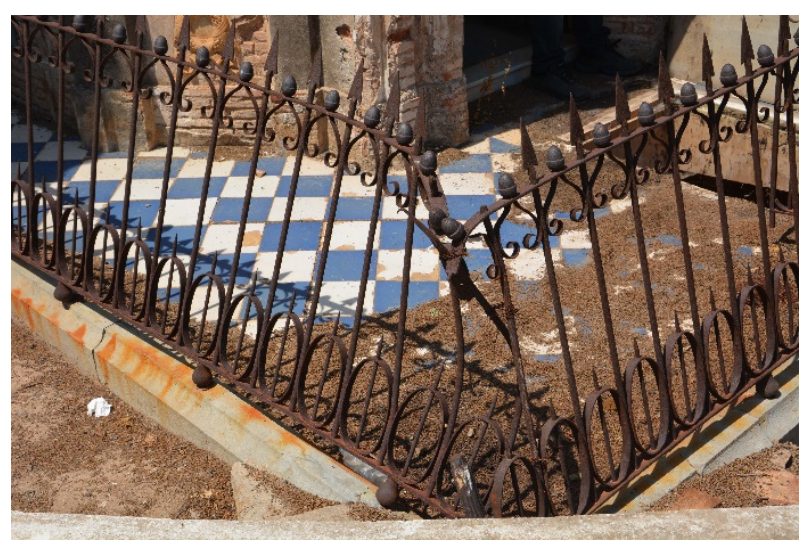

Figure 5: The northeast side of the iron enclosure with its deformation.

\subsection{Survey and preliminary data processing}

The panteón data were collected in three different survey campaigns conducted in February, March and June 2020 (due to the restrictions caused by COVID-2019 emergency, the campaigns were limited). The collection of external and internal data was carried out simultaneously with Terrestrial Laser Scanner (TLS) and digital photogrammetry. Fourteen scans were performed with a Trimble TX6 time-of-flight scanner. About 400 photos were processed with the Agisoft Metashape software, 1.5 .1 build 7618 (64 bit) in different chunks, joined by the coordinates obtained from the TLS point cloud. The final model is the result of the union of exterior, interior and roof. Other photos have been used for the realization of detail models, in particular the decorative elements present. 
Despite the small size of the artefact, the complexity of the decoration and the presence of trees near the building, led to some shortcomings in the digital reconstruction by photogrammetry, which were integrated with the mesh model created by the laser scanner point cloud (Fig. 6).

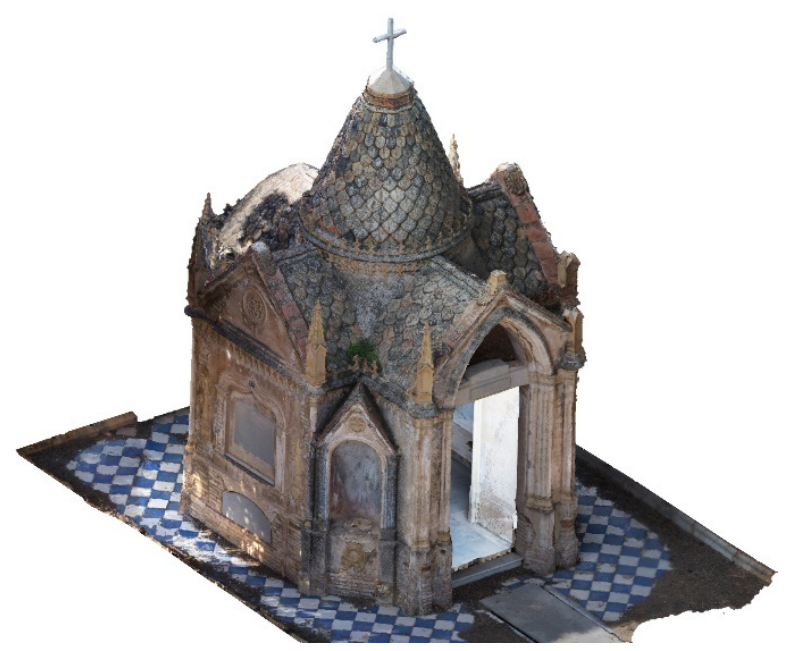

Figure 6: The mesh model produced with Agisoft Metashape.

Once the preliminary model was completed, it was possible to extract detail sections for the production of 2D drawings and corresponding orthoimages. Plans and sections were then inserted into the BIM environment to create the basic model.

\section{Methodology for the creation of the HBIM model}

As already described in section 2.2, some preliminary elaborations were carried out with CAD methods, prior to the realization of the model in a BIM environment (a detailed report of survey and data processing can be found in Bertacchi, Juan-Vidal, Cipriani, \& Molina Sánchez, 2020).

In addition, the building point cloud has been inserted in the BIM file, in the same position of the previously set origin, to serve as a reference for subsequent modelling. The context was modelled by creating a topography and a building pad corresponding to the enclosure. The floors were created from the lines extrapolated from the point cloud, using the corresponding family. For the walls, which have a very articulated shape, an "In-place component" was created by extruding successive sections derived from the point cloud. For roofs, a mass was modelled which was then used as the basis for the "Roof by surface" tool. To this model were added all the specific elements that assemble the building (Fig. 7).

At the basis of the preparation of the BIM model some general observations were made for its correct execution. On the basis of the physical and geometrical characteristics of the building, the needs of the restorers were taken into consideration in order to create a tool that can be effectively used in the restoration project and at the same time keep open the possibilities of further development and processing of the raw material, both inside and outside the BIM environment (3D printing, enhancement of the heritage through the publication on online platforms for the visualization of the 3D model...).
An essential phase for the correct setting of the model was the cataloguing of all the elements that make up the building, in order to have a global control of the operations before the restoration. The concepts underlying the cataloguing are described below.

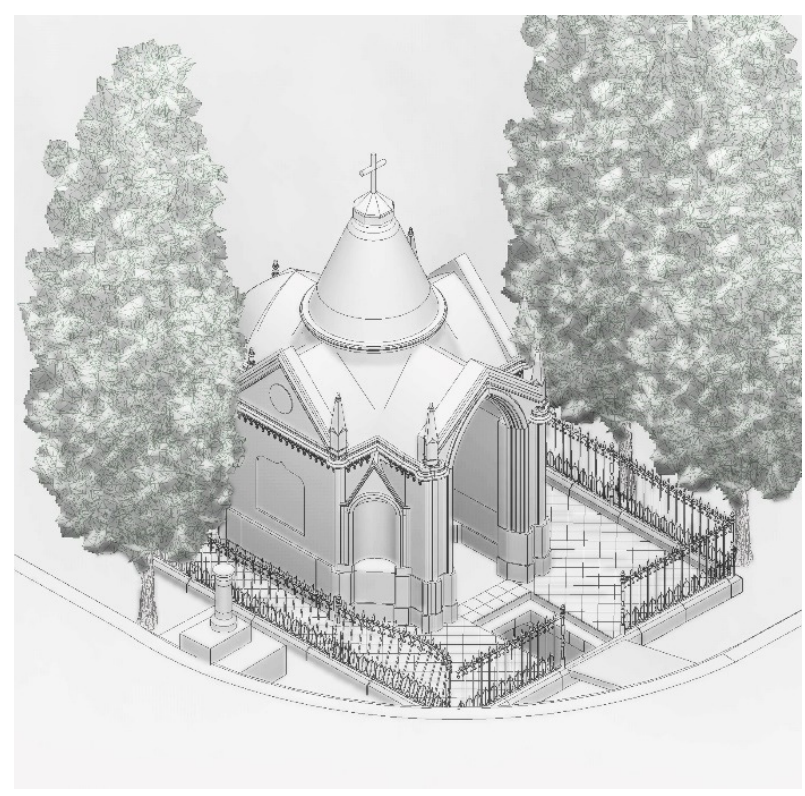

Figure 7: The BIM model in Autodesk Revit.

\subsection{Preliminary cataloguing}

The initial inspections revealed the need to have precise control over every element that makes up the panteón. For each type of element, it was necessary to be able to provide the restorers with detailed information, for example on the size, number of elements and state of conservation.

The cataloguing before the creation of the model was then used to define: the type of elements based on intrinsic physical characteristics such as material and dimensions; the number of elements for each type; the state of conservation. This information then determined the subsequent creation of the element families in Autodesk Revit v2019. In fact, for each family the characteristics and the information that it would have to report in order to meet the specific requirements of the restorers were clear a priori. The creation of the families will be further investigated by reporting some specific examples in section 3.2.

In order to insert in the BIM model the detailed models of the decorative elements with all this information, it was considered necessary to carry out a preventive cataloguing to facilitate the subsequent creation of the BIM families, so that restorers and maintainers can have a real advantage from the use of the model. The cataloguing therefore served as a basis to avoid errors in the design of the families. Being a completely manual and time-consuming phase and subject to possible compilation errors, it is considered necessary to try to avoid this phase in the future development of the project, when the creation of a library of common elements and the repetition of the workflow applied to this first case study will have solved this initial lack.

For the compilation of the catalogue, the panteón was previously divided into levels, each of which was 
interpreted with an acronym and with the addition of an " $\mathrm{i}$ " for internal and "e" for external. Each element was then assigned a code starting from an abbreviation of the name, a letter corresponding to the cardinal point of the side in which it is located and finally a progressive number of the element for each side of the building (Fig. 8). The code of each element makes it easy to understand its position in the building. Additional information on the type of material and state of conservation has been provided for each element in order to facilitate the preliminary assessment of the restoration operations to be carried out. The same approach to the assignment of the codes was also followed for the elements not currently present, but which were part of the original composition. The information in this case comes from a photo of the early twentieth century and it has been combined with the seriality of the presence of the same decorations. For each element it is therefore possible to proceed with the realization of the missing pieces, with the exception of a type of pinnacle, of which no exemplar remains, and the statue of an angel that originally crowned the central dome, of which only the photo and a piece of wing found on the roof remain.

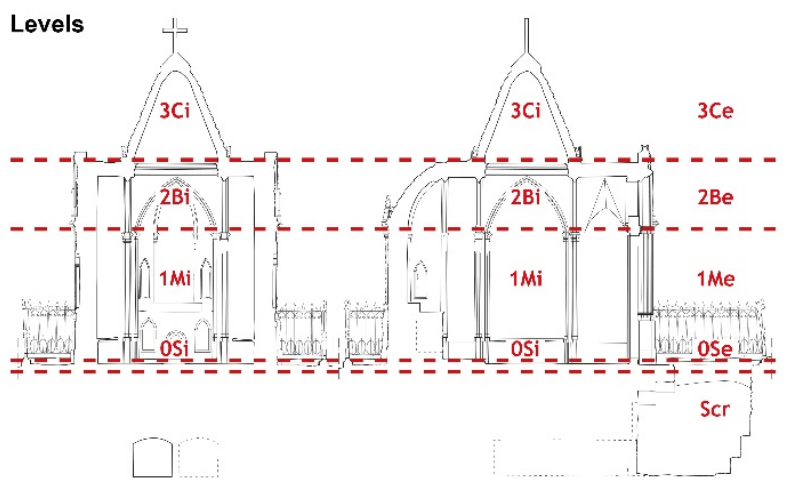

Figure 8: Level division in the catalogue.

Assigning a code to each element thus facilitates the creation of the families and makes it possible to create a phase of the model in which the original state of the chapel is reproduced.

\subsection{The HBIM model: creation of families}

To describe the methodology used, we report 4 specific cases that have been developed for the completion of the HBIM model. Each case is a reference to a typology of elements present in the panteón, so it can be applied to similar cases in different contexts.

First, the creation of the stone kerb that is part of the railing surrounding the building. The kerb is in limestone, with a particular section profile. Each single element has a different length and those at the corners have an $L$ shape. The main pathologies affecting the kerb are: damage with the detachment of substantial parts, mainly due to the expansion of the oxidised metal supports of the railing inserted in the stone; a high percentage of the surface covered by rust stains; some small cracks; the displacement of some elements from their original position (Fig. 9).

The restorers needed information on the total number of pieces, the length of each piece, the total surface area and the pathologies related to each element.
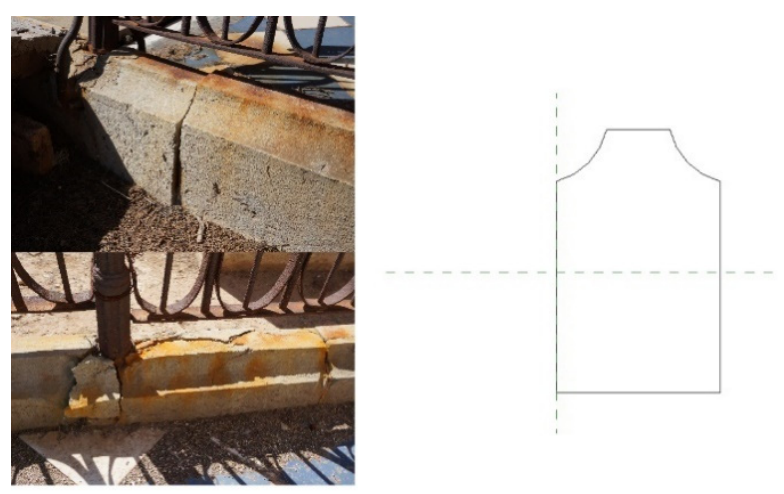

Figure 9: Some photos of the stone kerb and the profile in the Revit family editor.

The family created is a railing based one, with only the baluster active. The section profile obtained by the point cloud has simply been inserted into the family editor in a convenient position for subsequent insertion into the model (the origin corresponds to the reference level). A "limestone" material has been added to the family type. The kerb was inserted following the reference of the point cloud and separating each element from another as in the real condition. Then, in the "Mark" section the code established in the catalogue has been inserted and in the "Comments" the state of conservation has been provided, as a simple textual description.

All the information that has been linked to each element is easily accessible through the automatic schedule tool, which also offers the possibility of listing and counting the elements by Length or Comments or Code, as required (Fig. 10).

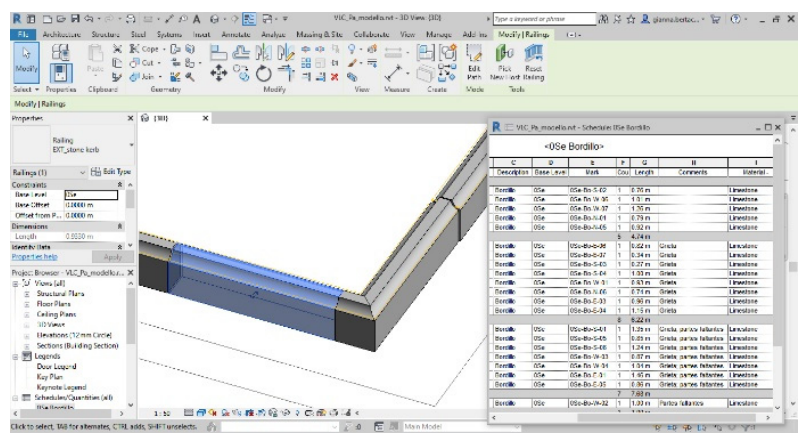

Figure 10: The stone kerb type in the model and the schedule with all the listed information and features.

The iron railing that leans on the kerb has been divided into sectors corresponding to those formed by the posts. Each sector of the railing consists of two horizontal bars and a variable number of modules. A single module consists of an arrow shaped bar and some decorative elements (Fig. 11).

Here, too, the restorers needed precise information on the number and condition of each individual element. In addition, some areas of the railing suffered damage that caused the loss of supports, verticality and shape (particularly in the northeast corner).

For these reasons it was important to recreate the railing following its current shape (to provide information on where and how to intervene and restore the original condition) and to recreate the division into modules (to add status information on broken or missing elements). 

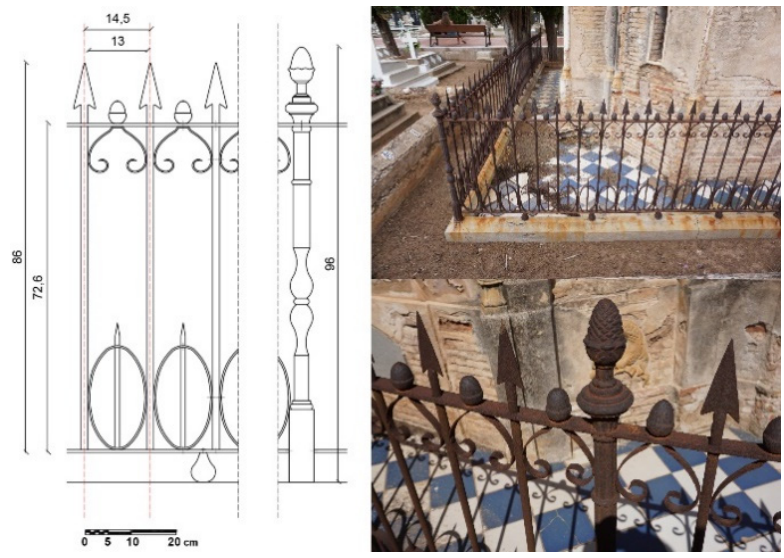

Figure 11: $C A D$ drawing of the railing module and some railing details.

The methodology undertaken began with the creation of surfaces (as "in-site mass") that followed the point cloud data. Then, for each sector a surface was created and automatically divided into the number of modules. This subdivision was then used to position the family types corresponding to each railing element.

Four different adaptive models were created from CADdrawn profiles, with extrusion or rotation commands. The different types of railing family can be easily positioned on the mass that forms each sector. Then, all the elements appear in the schedule, so they can be easily counted and report all the information added (Fig. 12).

Another procedure was used for the external floor. This is composed of alternately white and blue square ceramic tiles. For the floor it was necessary to know the total tile count for each different colour, size (if the tile was complete or cut) and condition of the material, to decide whether to replace or restore it.

In order to have the possibility to quickly list all the elements according to these specific parameters, we decided to divide the floor into parts. Once the floor had been set, with the "Create parts" tool and the use of the $C A D$ drawing, the floor was divided according to the position of the tiles. Then, some specific parameters were added to the category (type of parameter Yes/No): Broken, Lack of varnish, Serious lack of varnish, Lack of material, Absent, No information. These parameters appear in the properties of each tile and can be easily selected if present (Fig. 13). Then they are listed and counted in the Schedule view, providing the necessary information for restoration work. For example, it is possible to know how many white tiles have a serious lack of varnish or are broken and therefore probably need to be replaced instead of being restored. The schedule analysis shows that blue tiles are in better condition than white ones.

Certainly, this subdivision is useful not only during the restoration phase, but also to add information about the restored or replaced parts during the monitoring phase.

Finally, the last example describes the process used for a ceramic decorative element that forms a frame at the top of the wall. This is probably one of the standard elements produced during the construction period of the chapel. The model was made in two versions: the first, a highly detailed model derived from the curves extrapolated from the photogrammetric model, and the second, a simplified geometry recreated in a line-based family. The component can then be added directly following the wall sectors on which it appears (Fig. 14).

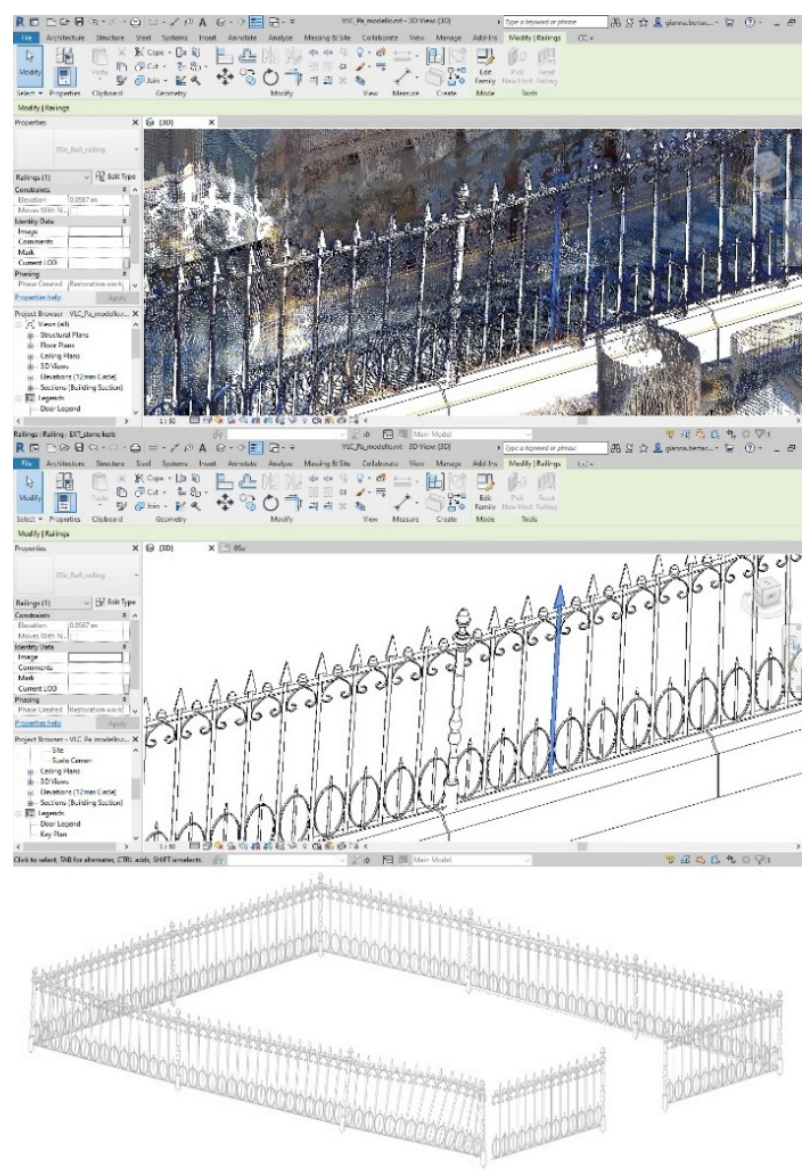

Figure 12: The subdivision of the surface into modules and its correspondence with the point cloud. In the final railing the possibility to select a single element of a module and add specific information is active.

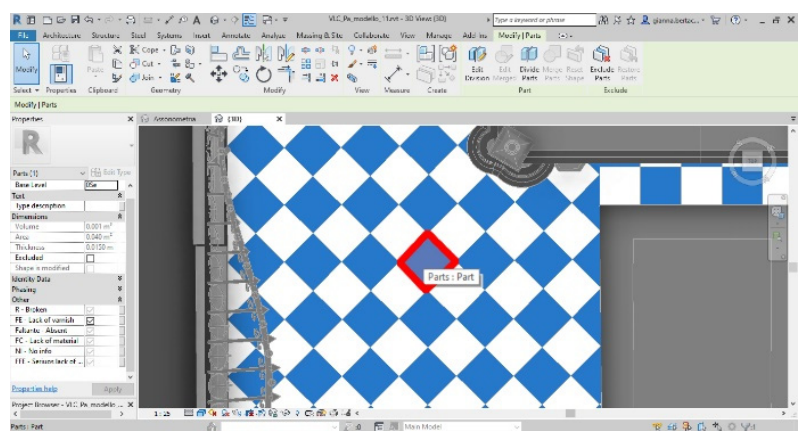

Figure 13: The parts that form the floor: each one is selectable, and all the necessary information can be added.

As with the other examples, the characteristics and information of each element can be listed automatically with the schedule view.

\section{Future developments and conclusions}

This document describes the methodology adopted to create an HBIM model of a particular cultural asset. As indicated in the introduction on the state of the art, HBIM experiments clash with some practical and theoretical problems. The main ones concern the modelling phase 
(all actions needed to transform raw data into BIM elements), and the design phase (to understand the best solution for creating an element that provides what end users need).

Given the technological development, some problems of the first category are being solved, although there are not yet tools as easy to use as in software like McNeel Rhinoceros. Given the peculiarities of the heritage assets, for now experimentation and differentiation of workflows according to each element is still predominant, and the scarce modelling tools slow down the workflow and make it rigid.

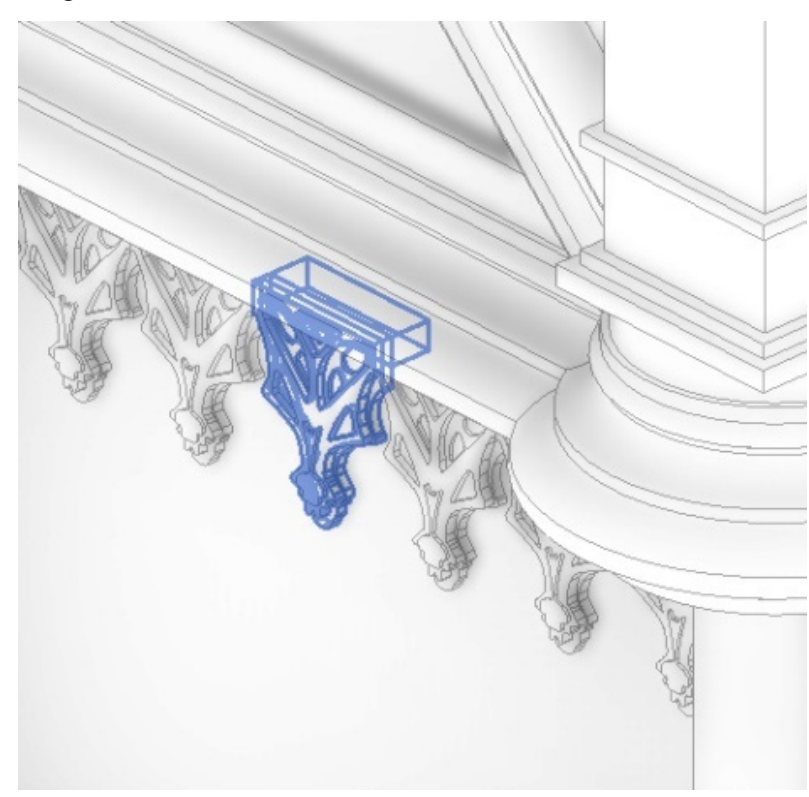

Figure 14: The decoration added on the upper part of the outer wall.

On the other hand, after the initial effort, what can be achieved with the BIM models created, in terms of fast counting and adding information, is the real saving in terms of time, and also opens up to different possibilities and users (static analysis, energy studies, etc.).

The paper presents some specific examples of the modelling workflow carried out on a small but complex building, which in itself contains peculiarities that have allowed diversified experiments on the elements. Each of the workflows presented derives not only from the initial intrinsic conditions of the single element, but from the combination of the physical parameters (shape, material, arrangement...) with the characteristics of the BIM software (families, parameters, links to external objects...) and with the needs of use (counting, mapping, volume, area, state of conservation...). The interaction and combination of these parameters are essential for the correct creation of families and types to be inserted in the model. Moreover, the variety of typologies analysed and their flexibility allows their application to objects at different scales and in different contexts.
Therefore, the approach that has been maintained in the case of such a complex building is one of maximum flexibility, not only in the BIM model creation phase, but also in the raw data processing phase for the parallel creation of models with different details and for different purposes, which can always be added to the BIM model as a link to a database. This partially solves the still existing difficulty in processing the huge amounts of data that generally characterise the documentation of the built heritage. Moreover, the bases are prepared for different uses of three-dimensional models at different treatment levels (think of the potential of automatic segmentation or automatic recognition of pathologies for surface mapping or 3D printing of missing or to be replaced elements). The $3 \mathrm{D}$ reality-based models therefore play a complementary role to the HBIM model in documentation and restoration work and are prepared for specific uses, such as high detail texture visualisation, 3D printing, heritage dissemination via online platforms.

In conclusion, the most unresolved issues concern modelling and model setting problems.

While the first can be solved by looking for the workflow that best suits each type of element, the second depends on the setting of the whole project. In this sense, the examples presented in detail in section 3.2 are the result of a previous reasoning which, thanks to manual cataloguing and in-depth study of the construction and architectural characteristics of the chapel, made it possible to logically execute the parts created and the model. In essence, the creation of the BIM model did not occur by juxtaposition of parts, but by following the construction logic, combined with the potential offered by the software to satisfy specific requests. These requests were mainly highlighted by the restorers of the Instituto de Restauración del Patrimonio themselves, in order to really obtain from the model the information necessary for the restoration work.

The flexible approach to project components lays the foundations for future developments and applications in similar projects, for which the BIM model can be set up following the guidelines of this pilot project. Those families created can also be reused or easily adapted in other similar projects (as better described in section 2).

The creation of a library of standardised elements belonging to neogothic architectures stylistically and historically linked to the Castellón chapel, together with the continuous experimentation of specific workflows for the creation of families in a similar context, are the main aspects in continuous development.

\section{Acknowledgements}

Authors would like to thank: the municipality of Castellón de la Plana, the Instituto de Restauración del Patrimonio of the Universitat Politècnica de València, professors José Herráez Boquera and José Luís Denia Ríos for facilitating access to the laser scanner and Susana Molina Sánchez for the help provided during the survey operations.

\section{References}

Adembri, B., Alonso-Durá, A., Juan-Vidal, F., Bertacchi, G., Bertacchi, S., Cipriani, L., Fantini, F., \& Soriano-Estevalis, B. (2016). Modelli digitali 3D per documentare, conoscere ed analizzare l'architettura e la costruzione nel mondo antico: 
l'esempio della Sala Ottagonale delle Piccole Terme di Villa Adriana. Archeologia e Calcolatori, XXVII, 291-316.

Apollonio, F. I., Gaiani, M., \& Bertacchi, S. (2019). Managing Cultural Heritage with integrated services platform. Int Arch Photogramm Remote Sens Spatial Inf Sci, XLII-2/W11, 91-98. https://doi.org/10.5194/isprs-archives-XLII-2-W11-912019

Banfi, F. (2017). BIM Orientation: Grades of Generation and Information for Different Type of Analysis and Management Process. Int Arch Photogramm Remote Sens Spatial Inf Sci XLII-2/W5, 57-64. https://doi.org/10.5194/isprs-archivesXLII-2-W5-57-2017

Banfi, F. (2020). HBIM, 3D drawing and virtual reality for archaeological sites and ancient ruins. Virtual Archaeology Review, 11(23), 16-33. https://doi.org/10.4995/var.2020.12416

Bertacchi, S., Bertacchi, G. \& Cipriani, L. (2021). Chiuro laboratory: integration of workflows from digital survey to optimised 3D urban models for interactive exploration. Appl. Geomat. https://doi.org/10.1007/s12518-020-00352-1

Bertacchi, G., Juan-Vidal, F., Cipriani, L., \& Molina Sánchez, S. (2020). Levantamiento digital del Panteón de Ramón Peres y Rovira en el cementerio de Castellón de la Plana (Valencia, España). Arché, 13 - 14 - 15, $171-180$. http://hdl.handle.net/10251/156576

Biagini, C., \& Donato, V. (2016). Levels of development for historic building information modeling: towards building simulation. UID2016 - XXXVIII Convegno internazionale dei Docenti delle Discipline della Rappresentazione, XIII Congresso della Unione Italiana del Disegno - Le ragioni del disegno - pensiero, forme e modello nella gestione della complessità, Florence, Italy. 1045-1050.

Bolognesi, C., \& Caffi, V. (2019). Extraction of primitives and objects from HSHAPES, Int. Arch. Photogramm. Remote Sens. Spatial Inf. Sci., XLII-2/W9, 151-156. https://doi.org/10.5194/isprs-archives-XLII-2-W9-151-2019

Brumana, R., Banfi, F., Cantini, L., Previtali, M., \& Della Torre, S. (2019). HBIM Level of Detail-Geometry-Accuracy and survey analysis for architectural preservation. Int. Arch. Photogramm. Remote Sens. Spatial Inf. Sci., XLII-2/W11, 293-299. https://doi.org/10.5194/isprs-archives-XLII-2-W11-293-2019

Castellano-Román, M. \& Pinto-Puerto, F. (2019). Dimensions and Levels of Knowledge in Heritage Building Information Modelling, HBIM: The model of the Charterhouse of Jerez (Cádiz, Spain). Digital Applications in Archaeology and Cultural Heritage, 14. https://doi.org/10.1016/j.daach.2019.e00110

Cipriani, L., Bertacchi, S., \& Bertacchi, G. (2019). An optimised workflow for the interactive experience with Cultural Heritage through reality-based 3D models: cases study in archaeological and urban complexes. Int Arch Photogramm Remote Sens Spatial Inf Sci XLII-2/W11, 427-434. https://doi.org/10.5194/isprs-archives-XLII-2-W11427-2019

Cipriani, L. \& Fantini, F. (2018). Integration of Pipelines and Open Issues in Heritage Digitisation. In: Remondino, F., Georgopoulos, A., González-Aguilera, D. \& P. Agrafiotis (Eds) Latest Developments in Reality-Based 3D Surveying and Modelling. Basel (CH), MDPI, 171-191. https://doi.org/10.3390/books978-3-03842-685-1-8

Chiabrando, F., Lo Turco, M., and Rinaudo, F. (2017). Modeling the decay in an HBIM starting from 3D point clouds. A followed approach for Cultural Heritage knowledge. ISPRS - International Archives of the Photogrammetry, Remote Sensing and Spatial Information Sciences, 62, 605-612, 2017. https://doi.org/10.5194/isprs-archives-XLII-2-W5-6052017

Diara, F., \& Rinaudo, F. (2018). Open source HBIM for Cultural Heritage: a project proposal. Int. Arch. Photogramm. Remote Sens. Spatial Inf. Sci., XLII-2, 303-309. https://doi.org/10.5194/isprs-archives-XLII-2-303-2018

Dore, C., \& Murphy, M. (2012). Integration of Historic Building Information Modeling and 3D GIS for Recording and Managing Cultural Heritage Sites. $18^{\text {th }}$ International Conference on Virtual Systems and Multimedia: "Virtual Systems in the Information Society", 2-5 September. 2012, Milan, Italy. 369-376.

Dore, C., \& Murphy, M. (2017). Current state of the art Historic Building Information Modelling. ISPRS - International Archives of the Photogrammetry, Remote Sensing and Spatial Information Sciences, XLII-2/W5, $185-192$. https://doi.org/10.5194/isprs-archives-XLII-2-W5-185-2017

Grilli, E., \& Remondino, F. (2019). Classification of 3D Digital Heritage. Remote Sens., $11,847$. https://doi.org/10.3390/rs11070847

Heesom, D., Boden, P., Hatfield, A., Rooble, S., Andrews, K. \& Berwari, H. (2020). Developing a collaborative HBIM to integrate tangible and intangible cultural heritage. Int. J. Building Pathology and Adaptation, 2020. https://doi.org/10.1108/IJBPA-04-2019-0036

Jiang, Y., Li, A., Xie, L., Hou, M., Qi, Y., \& Liu, H. (2020). Development and Application of an Intelligent Modeling Method for Ancient Wooden Architecture. ISPRS Int. J. Geo-Inf., 9, 167. https://doi.org/10.3390/ijgi9030167

López, F.J., Lerones, P.M., Llamas, J., Gómez-García-Bermejo, J., \& Zalama, E. (2018). A Review of Heritage Building Information Modeling (H-BIM). Multimodal Technologies Interact 2(2), 21. https://doi.org/10.3390/mti2020021

Massafra, A., Prati, D., Predari, G., \& Gulli, R. (2020). Wooden Truss Analysis, Preservation Strategies, and Digital Documentation through Parametric 3D Modeling and HBIM Workflow. Sustainability, 12, 4975. 
https://doi.org/10.3390/su12124975

Molina Coronado, E. (2017) La historia de Castellón llama a la puerta y reclama derecho a la memoria el 1 de noviembre. Memoria histórica del Cementerio de San José de Castellón | Castellón Información. Retrieved March 15, 2021, from http://www.castelloninformacion.com/memoria-historica-del-cementerio-de-san-jose-de-castellon/

Mol, A., Cabaleiro, M., Sousa, H. S., \& Branco, J. M. (2020). HBIM for storing life-cycle data regarding decay and damage in existing timber structures. Automation in Construction, 117, 1032622. https://doi.org/10.1016/j.autcon.2020.103262

Ortells Chabrera, V. (2005). La indústria ceràmica a la Plana de Castelló. Tradició històrica i mundialització actual. Treballs de la Societat Catalana de Geografia, 58, 35-66.

Pierdicca, R., Paolanti, M., Matrone, F., Martini, M., Morbidoni, C., Malinverni, E. S., Frontoni, E., \& Lingua, A. M. (2020). Point Cloud Semantic Segmentation Using a Deep Learning Framework for Cultural Heritage. Remote Sens., 12, 1005. https://doi.org/10.3390/rs12061005

Pocobelli, D. P., Boehm, J., Bryan, P., Still, J., \& Grau-Bové, J. (2018). BIM for heritage science: a review. Heritage Science 6:30. https://doi.org/10.1186/s40494-018-0191-4

Salvador-García, E., García-Valldecabres, J., \& Viñals-Blasco, M. J. (2018). The use of HBIM models as a tool for dissemination and public use management of historical architecture: a review. International Journal of Sustainable Development and Planning. 13(1), 96-107. https://doi.org/10.2495/SDP-V13-N1-96-107

Sun, Z., Xie, J., Zhang, Y., \& Cao, Y. (2019). As-Built BIM for a Fifteenth-Century Chinese Brick Structure at Various LoDs. ISPRS Int. J. Geo-Inf., 8. 577. https://doi.org/10.3390/ijgi8120577

Tsilimantou, E., Delegou, E. T., Nikitakos, I. A., loannidis, C., \& Moropoulou, A. (2020). GIS and BIM as Integrated Digital Environments for Modeling and Monitoring of Historic Buildings. Appl. Sci., 10, 1078. https://doi.org/10.3390/app10031078 